\title{
Deficit Irrigation Reduces Postharvest Rib Pinking in Wholehead Iceberg Lettuce, but at the Expense of Head Fresh Weight
}

by Monaghan, J.M., Vickers, L.H., Grove, I.G. and Beacham, A.M.

Copyright, Publisher and Additional Information: This is the author accepted manuscript. The final published version (version of record) is available online via Wiley Please refer to any applicable terms of use of the publisher.

DOI: 10.1002/jsfa.7895

Harper Adams

University

Monaghan, J.M., Vickers, L.H., Grove, I.G. and Beacham, A.M. 2016. Deficit Irrigation Reduces Postharvest Rib Pinking in Wholehead Iceberg Lettuce, but at the Expense of Head Fresh Weight. Journal of the Science of Food and Agriculture. 


\section{Deficit Irrigation Reduces Postharvest Rib Pinking in Wholehead Iceberg Lettuce, but at the Expense of Head Fresh Weight}

\begin{tabular}{|r|l|}
\hline Journal: & Journal of the Science of Food and Agriculture \\
\hline Manuscript ID & JSFA-16-0894.R1 \\
\hline Wiley - Manuscript type: & Research Article \\
\hline Complete List of Authors: & $\begin{array}{l}\text { Monaghan, James; Harper Adams University, Crop and Environment } \\
\text { Sciences Department } \\
\text { Vickers, Laura; Harper Adams University, Crop and Environment Sciences } \\
\text { Grove, Ivan; Harper Adams University, Crop and Environment Sciences } \\
\text { Beacham, Andrew; Harper Adams University, Crop and Environment } \\
\text { Sciences }\end{array}$ \\
\hline Key Words: & Lettuce, Lactuca sativa, Deficit Irrigation, Pinking, Postharvest \\
\hline \multicolumn{2}{|c}{} \\
\hline
\end{tabular}


1

2 Deficit Irrigation Reduces Postharvest Rib Pinking in Wholehead Iceberg Lettuce, but at the

3

4

5

6

7

8

Expense of Head Fresh Weight

\section{RUNNING TITLE}

Influence of irrigation on lettuce postharvest pinking

AUTHORS

\author{
James M Monaghan ${ }^{\text {a }}$ Laura H Vickers, Ivan G Grove and Andrew M Beacham \\ Fresh Produce Research Centre, Crop and Environment Sciences Department, Harper Adams \\ University, Edgmond, Shropshire, TF10 8NB, UK \\ aAuthor for correspondence: jmonaghan@harper-adams.ac.uk
}

\section{ABSTRACT}

BACKGROUND: Postharvest pinking is a serious issue affecting lettuce quality. Previous studies suggested the possibility of using deficit irrigation to control discolouration, however, this approach may also affect yield. This study investigated the effect of varying irrigation deficits on iceberg lettuce (Lactuca sativa L.) to determine the relationship between irrigation deficit, pinking and fresh weight. RESULTS: The deficit imposed and head fresh weight obtained depended on both the duration and timing of withholding irrigation. Withholding irrigation for a period of two or three weeks in the middle or end of the growth period significantly reduced rib pinking compared to well-watered controls. Withholding irrigation for two weeks at the start of the growth period or one week at the end did not significantly reduce 1 
24 pinking. Withholding irrigation also reduced head fresh weight such that minimising pinking 25 would be predicted to incur a loss of $40 \%$ relative to well-watered controls. However, smaller benefits to pinking reduction were achieved with less effect on head fresh weight.

27 CONCLUSION: Deficit irrigation could therefore be used to provide smaller but higher quality 28 heads which are less likely to be rejected. The balance of these factors will determine the degree 29 of adoption of this approach to growers.

\section{INTRODUCTION}

Product appearance is a key performance trait in fresh produce, with both pre- and post-harvest quality important for shelf life and consumer consideration. In wholehead lettuce (Lactuca sativa L.), discolouration of the ribs, a problem known as rib pinking, is a major concern in maintaining product quality.

39 Pinking is thought to represent a physiological response of the plant and often occurs after 40 wounding. ${ }^{1-3}$ Upon wounding, the production of ethylene and phenolics by the plant is 41 increased, together with an increase in the activity of the enzymes phenylalanine ammonia-lyase 42 (PAL) and polyphenol oxidase (PPO). ${ }^{2,4}$ Levels of phenolics, PPO and PAL activity have been 43 found to associate with the amount of rib discolouration in some studies though not in all. ${ }^{1,5}$. 44 However, rib pinking can often occur without prior tissue damage and this type of 45 discolouration has received relatively little attention to date.

46 A number of factors have been found to affect the incidence of pinking in lettuce, such as time 47 of transplanting, head maturity ${ }^{6}$ and lettuce type or genotype. ${ }^{1,7-8}$ Heat stress can also induce 
48 lettuce discolouration, the incidence and severity of which is affected by the timing of the stress

49 but is not affected by stress duration or night time temperature. ${ }^{9}$

50 Climate uncertainty, reduced water supplies and increasing drought frequency mean that raising

51 the water use efficiency of crops is becoming of increasing importance. ${ }^{10}$ As well as increasing

52 water use efficiency, precision irrigation may also act to improve product quality. Indeed, high

53 levels of irrigation have been found to increase PAL and PPO activity and microbial load at

54 harvest and to reduce the visual quality and fresh weight of lettuce. ${ }^{5,11}$ Reduced irrigation (30-

$5550 \mathrm{~mm}$ water deficit) has been shown to increase shelf life ${ }^{7}$ and reduce postharvest browning, ${ }^{11}$

56 however, it can also lead to reduced fresh weight, leaf number, leaf area index and dry matter

57 accumulation. ${ }^{11-13}$ The high water content of lettuce (around 95\%), means that a loss of around

$585 \%$ fresh weight due to reduced water content can affect lettuce appearance and saleability. ${ }^{14}$

59 Previous studies have investigated the effect of deficit irrigation on yield and browning. ${ }^{5,11}$ To

60 our knowledge, this is the first study that considers both duration and timing of deficit irrigation

61 and the effects on postharvest pinking. Using a number of irrigation deficit schemes imposed on

62 polytunnel-grown lettuce in three experiments, the feasibility of this approach was investigated

63 to minimise postharvest rib pinking in wholehead lettuce whilst also determining the potential

64 effects on yield. It was hypothesised that: 1) withholding irrigation for periods of varying

65 duration and timing within the growth season would produce a range of imposed water deficits

66 upon the plants; 2) that such deficits may also impact upon head fresh weight, and; 3) that water

67 deficits could reduce the extent of postharvest rib pinking. Finally, the relationship between

68 head fresh weight and pinking was investigated to determine whether it is possible to use deficit

69 irrigation to control postharvest pinking whilst minimising yield loss. 
73 The experiments were performed in a polytunnel at the Crop and Environment Research Centre 74 at Harper Adams University (Shropshire, UK). Soil taken from the location of the polytunnel 75 was used to fill plastic bins ( $40.0 \times 44.5 \times 76.5 \mathrm{~cm}$, total capacity $136 \mathrm{l})$, which were sunk into 76 the ground so that the top of the bin was approximately $30 \mathrm{~cm}$ above ground level. Holes were 77 drilled in the bin bases for drainage and the soil was allowed to settle and the bins topped up. 78 The soil was analysed by standard procedures and was identified as sandy loam with an average $\mathrm{pH}$ of 6.4 and average organic matter content of $15 \%$. The top $30 \mathrm{~cm}$ of soil was tilled after each crop and the soil below $30 \mathrm{~cm}$ was not disturbed. Six blocks of eight bins each were used in a $6 \times 8$ arrangement with a total of 12 bins per treatment in each experiment. Nitrogen (125

$82 \mathrm{~kg} / \mathrm{ha}$ ) was applied to the bins as a liquid feed prior to Experiment 1 . Fertiliser at a rate of $50 \mathrm{~kg}$ $83 \mathrm{P} / \mathrm{ha}, 275 \mathrm{~kg} \mathrm{~K} / \mathrm{ha}, 160 \mathrm{~kg} \mathrm{~N} / \mathrm{ha}$ was added to the bins prior to the start of Experiment 2. Prior to 84 Experiment 3, the bins received $150 \mathrm{~kg} /$ ha nitrogen. Four commercially propagated transplants of iceberg lettuce (Lactuca sativa L.) cv. Antarctica (obtained from PDM Produce, Shropshire, UK) at 4-5 true leaf stage were planted in each bin at $30 \mathrm{~cm}$ spacing. Experiment 1 began on 23/7/2012, Experiment 2 on 7/5/2013 and Experiment 3 on 3/7/2013. Irrigation treatments (beginning of Week 1) began after allowing transplant establishment. The average daily temperature in the polytunnel during the experiments ranged from $12.8^{\circ} \mathrm{C}$ and $23.4^{\circ} \mathrm{C}$. Data collection

91 Each bin had a central access tube for moisture content recording. Soil moisture content of the top $30 \mathrm{~cm}$ of the soil profile in each bin was monitored using a Diviner 2000 Soil Moisture

93 Probe (Sentek Technologies, Stepney, Australia) before and 24 hours after irrigation, which was 94 applied weekly. After establishment in the polytunnel bins, the plants were grown for six weeks 95 then assessed destructively. To provide the different irrigation treatments, watering was 96 withheld during certain weeks within this six week period, as indicated in Table 1. This 97 provided periods of varying duration and timing within the six weeks where the plants did not 98 receive water. The treatments were repeated twice for all timings except Wk 1-2. Irrigation 99 volumes were calculated to return the bins not undergoing deficit to approximately $95 \%$ field 4 
capacity. Accumulated relative deficit was calculated by comparing the moisture content of the bins during the deficit treatment period to that of the well-watered control bin in the same block.

Plants were grown to commercial maturity then harvested. At harvest, plants were cut at the 103 base, the waste was trimmed and the resulting head fresh weight recorded for each of the four plants per bin and then calculated relative to that of the plants from the well-watered control bin in the same block to allow for seasonal variation in well-watered head weight. The head of one plant per bin was dried in an oven at $80^{\circ} \mathrm{C}$ for 5 days in order to determine moisture content.

107 Another head from each bin was wrapped in a perforated bag and placed in an unlit cold store $108\left(1-5^{\circ} \mathrm{C}\right)$. Wholehead pinking on the $10 \mathrm{~cm}$ visible length of ribs from the butt was scored after ten days of storage using visual assessment criteria, marking from 1 (absence of pinking (white rib)), through 2 (pink colouration on $1 / 3$ of rib tissue), 3 (pink colouration on $2 / 3$ of rib tissue) to 4 (pink colouration on all of rib tissue). Plants were handled carefully to avoid damage to rib 112 tissue.

Statistical analyses

Tukey's multiple comparison test was used to determine significant differences between 115 treatment means after Analysis of Variance (ANOVA, $P \leq 0.05$ ). All statistical analyses were 116 performed using GenStat 14th Edition software (Genstat $14^{\text {th }}$ Edition; VSN International Ltd, 117 Hemel Hempstead, UK).

\section{RESULTS AND DISCUSSION}

Across the three experiments, withholding irrigation from growing lettuce plants for a range of 121 durations and at different stages of growth provided a range of imposed water deficits when compared to well-watered controls (Figure 1, Table 1). Comparing the withholding of irrigation for weeks 1-2, 3-4 or 5-6, indicated that for periods of the same duration ( 2 weeks), the later in

124 the growth period the irrigation is withheld, the larger the resulting deficit imposed, 
125 significantly so by weeks 5-6 (Figure 1). This is likely due to an increased water demand of

126 larger, more mature plants possessing a greater leaf area for transpiration. In addition, by

127 comparing the accumulated relative deficit imposed by withholding irrigation for a period of 1 ,

1282 or 3 weeks during the second half of the growth period, as the duration of irrigation

129 withholding increased, the deficit imposed upon the plants undergoing treatment increased

130 significantly (Figure 1).

131 Deficits imposed later in the growth period resulted in a greater weight loss, with the relative 132 head fresh weight being significantly lower for plants with irrigation withheld in weeks 5-6 than 133 in weeks 1-2 or 3-4 (Figure 1). In addition, the relative head fresh weight was significantly 134 lower when irrigation was withheld for a period of two or three weeks compared to one week. It 135 appears that withholding irrigation for one week late in the growing period (week 6) has a 136 similar effect to the two week treatments imposed earlier in the growth period (weeks 1-2 or 3137 4), probably due to the higher rates of evapotranspiration occurring from plants with greater leaf 138 area later in the growth period (Figure 1).

139 The effect of accumulated relative deficit on relative head fresh weight indicated a negative 140 relationship such that, for example, an accumulated relative deficit of $30 \mathrm{~mm}$ water was 141 sufficient to lower the relative head fresh weight of lettuce heads by $18 \%$, while a deficit of 100 $142 \mathrm{~mm}$ water lowered the head fresh weight by $47 \%$ (Figure 2). This finding agrees with those of 143 other studies where deficit irrigation impacted negatively on yield. ${ }^{11-13}$ However, as the 144 accumulated relative deficit increased further, so the effect on relative head fresh weight 145 decreased such that even at the highest deficit imposed in our experiments $(151 \mathrm{~mm})$, relative 146 head fresh weight remained at around $45 \%$ of the well-watered plants. It appears that even a 147 modest irrigation deficit can reduce head fresh weight; however, the plant appears to be able to 148 limit this loss to a maximum of around $55 \%$. The plants were grown in uniform soils to a depth 149 of $70 \mathrm{~cm}$ and it is likely that lettuce roots accessed water deeper in the profile in response to 150 drying soils in the top of the profile to limit head fresh weight loss at high deficits. ${ }^{15}$ 
151 Comparison of the rib pinking scores of lettuce in the different deficit irrigation schemes

152 (Figure 3) indicated that withholding irrigation for a period of two or more weeks in the mid to 153 late growth period (weeks 3-4, 5-6 and 4-6) significantly reduced pinking when compared to well-watered controls. Withholding irrigation either early in the growth period (weeks 1-2) or for one week at the end of the growth period (week 6) did not significantly reduce pinking. It appears that deficit irrigation is less effective in reducing pinking when used early in the growth period or when used for a short period of time, such as one week. This may reflect the imposition of an insufficiently large water deficit in these treatments to affect pinking development. This finding is in agreement with an earlier study that found reduced postharvest discolouration in lettuces which had undergone reduced irrigation. ${ }^{11}$ However, another report found that the cessation of irrigation for up to 16 days prior to harvest did not significantly affect pinking of lettuce ribs after up to 21 days in cold storage. ${ }^{16}$ It is interesting also to note that pinking appears to be unaffected by whether drip or overhead irrigation is used. ${ }^{6}$

For deficit irrigation to be considered a useful means to reduce postharvest pinking, negative effects on yield must be minimised. In order to determine the feasibility of this approach, the relative head fresh weight and lettuce pinking scores obtained from the deficit experiments was compared (Figure 4). This showed that reducing the rib pinking score to a minimal level would be associated with a head fresh weight loss of $40 \%$, a level of yield reduction that would not be commercially viable. However, smaller reductions in pinking could be achieved with a smaller reduction in head fresh weight by using a milder deficit treatment. For example, a reduction in pinking score from 1.86 for the well-watered control to 1.33 would be predicted to be achieved with a head fresh weight loss of $20 \%$, corresponding to an accumulated relative deficit of 35 $\mathrm{mm}$ water. The balance of the beneficial effect on pinking and negative effect on head fresh weight when using deficit irrigation remains to be decided by the grower. Whilst deficit irrigation leads to smaller heads, they show reduced pinking, and would be predicted to lead to a lower proportion of rejected heads, meaning that the resulting overall yield and financial cost of using deficit irrigation may not be as large as first appears, particularly for processed lettuce. 
178 Pinking may appear to be related solely to head size and therefore an earlier harvest would be 179 predicted to show the same effect on pinking as deficit irrigation and would be interesting for 180 future investigation. However, the plants grown with deficit irrigation in this study were the 181 same age as the well-watered controls and the number of leaves in the head at harvest did not 182 differ significantly from the well-watered controls (mean of 23.7 leaves for well-watered and 18323.6 leaves for deficit irrigation schemes), suggesting that they were at the same developmental stage. The effect of deficit irrigation on pinking therefore does not appear to simply represent slower development of the plants. If all plants were at the same age and developmental stage, then the difference in head fresh weight between well-watered and deficit irrigation plants will mainly reflect a difference in head moisture content, and postharvest discolouration has been associated with high head moisture content at harvest. ${ }^{11}$ When pinking severity was compared to head moisture content, it was found that lower head moisture contents were associated with lower pinking scores (Table 1) and that pinking scores were more variable at high moisture contents. As pinking is often associated with wounding of the plant tissue , ${ }^{1-3,11}$ so reducing moisture content may act to reduce pinking by limiting damage as the rib tissue is less turgid. Indeed, lower moisture content has been found to be associated with better maintenance of visual quality during storage and lower percentage of damaged leaves in minimally processed babyleaf spinach (Spinacia oleracea L. ${ }^{17}$ and butterhead lettuce. ${ }^{18}$ Pinking has also been associated with the presence of the bacterium Pseudomonas marginalis. ${ }^{7}$ This species was isolated from pink rib legions while injection into the rib led to pinking symptoms. Wounding may therefore aid colonisation by bacteria and subsequently increase pinking in this manner also.

\section{CONCLUSIONS}

Whilst deficit irrigation does not appear to be feasible for the complete elimination of rib pinking in whole head lettuce, it is still able to contribute to improving postharvest quality in lettuce when used in moderation. Growers will therefore need to balance the potential beneficial 
effects of deficit irrigation on rib pinking and the associated risk of rejected lettuce heads on quality parameters, with a commercially acceptable reduction in head fresh weight.

206

207

\section{ACKNOWLEDGEMENTS}

208

209

210

211

212

213

214

215

216

217

218

219

220

221

222

The authors wish to acknowledge the UK Government Department for Environment, Food and Rural Affairs (DEFRA) HortLINK Programme for funding this project. Some aspects of the work are summarised in HortLINK Final Project Report HL0196.

\section{REFERENCES}

1. Sharples, GC, Biochemical Studies of Rib Discoloration and Pink Rib of Lettuce. Vegetable Report, University of Arizona Repository 15-19 (1965).

2. López-Galvez, G, Saltveit, $M$ and Cantwell, M, Wound-induced phenylalanine ammonia-lyase activity: factors affecting its induction and correlation with the quality of minimally processed lettuces. Postharvest Biol Technol 9: 223-233 (1996).

3. Tomás-Barberán, FA, Loaiza-Velarde, J, Bonfanti, A, Saltveit, ME, Early wound- and ethylene-induced changes in phenylpropanoid metabolism in harvested lettuce. $\mathrm{J} \mathrm{Am}$ Soc Hort Sci 122: 399-404 (1997).

4. Cantos, JA, Tudela, MI and Espína, JC, Phenolic compounds and related enzymes are not rate-limiting in browning development of fresh-cut potatoes. J Agric Food Chem 50: 3015-3023 (2002).

5. Luna, MC, Tudela, JA, Martínez-Sánchez, A, Allende, A and Gil, MI, Long-term deficit and excess of irrigation influences quality and browning related enzymes and phenolic metabolism of fresh-cut iceberg lettuce (Lactuca sativa L.) Postharvest Biol Technol 73: 37-45 (2012).

6. Hilton, HW, Clifford, SC, Wurr, DCE and Burton, KS, The influence of agronomic factors on the visual quality of fieldgrown, minimally-processed lettuce. $J$ Hort Sci Biotech 84(2): 193-198 (2009). 
230 7. Hall, CB, Stall, RE and Burdine, HW, Association of Pseudomonas marginalis with pink rib of lettuce. Florida Agriculture Experiment Stations Journal Series 4132: 163$165(1971)$.

8. Atkinson, L, Hilton, HW and Pink, DAC, A study of variation in the tendency for postharvest discolouration in a lettuce (Lactuca sativa) diversity set. Int J Food Sci Tech 48: 801-807 (2013).

9. Jenni, S, Rib discolouration: A physiological disorder induced by heat stress in crisphead lettuce. HortSci 40(7): 2031-2035 (2005).

10. Monaghan, JM, Daccache, A, Vickers, LH, Hess, TM, Weatherhead, EK, Grove, IG, Knox, JW, More 'crop per drop': constraints and opportunities for precision irrigation in European agriculture. J Sci Food Agric 93(5): 977-980 (2013).

11. Luna, MC, Tudela, JA, Martínez-Sánchez, A, Allende, A and Gil, MI, Optimizing water management to control respiration rate and reduce browning and microbial load of fresh-cut romaine lettuce. Postharvest Biol Technol 80: 9-17 (2013).

12. Gallardo, M, Jackson, LE, Schulbach, KF, Snyder, RL, Thompson, RB and Wyland, LJ, Production and water use in lettuces under variable water supply. Irrig Sci 16: 125-137 (1996).

13. Karam, F, Mounzer, O, Sarkis, F and Lahoud, R, Yield and nitrogen recovery of lettuce under different irrigation regimes. $J$ Appl Hort 4(2): 70-76 (2002).

14. Atkinson, L, Genetic Characterisation of Post Harvest Spoilage in Lettuce. Chapter 1: Introduction. $\mathrm{PhD}$ thesis, University of Warwick (2010).

15. Sharp, RE and Davies, WJ, Root growth and water uptake by maize plants in drying soil. J Exp Bot 36(9): 1441-1456 (1985).

16. Fonseca, JM, Postharvest quality and microbial population of head lettuce as affected by moisture at harvest. J Food Sci 71(2): M45-M49 (2006).

17. Medina, MS, Tudela, JA, Marin, A, Allende, A and Gil, MI, Short postharvest storage under low relative humidity improves quality and shelf life of minimally processed baby spinach (Spinacia oleracea L.). Postharvest Biol Technol 67: 1-9 (2012). 
1

2

3

4

5

6

7

8

9

10

11

12

13

14

15

16

17

18

19

20

21

22

23

24

25

26

27

28

29

30

31

32

33

34

35

36

37

38

39

40

41

42

43

44

45

46

47

48

49

50

51

52

53

54

55

56

57

58

59

60
258 18. Agüero, MV, Barg, MV, Yommi, A, Camelo, A and Roura, S, Postharvest changes in

259

260

with overall visual quality. J Food Sci 73(1): S47-S55 (2008). 
264 Table 1. Summary data for the three irrigation deficit experiments. Accumulated relative deficit 265 and relative head fresh weight are calculated relative to the well-watered control (WW, 266 irrigation not withheld) in each experiment. Wk $=$ week(s).

267

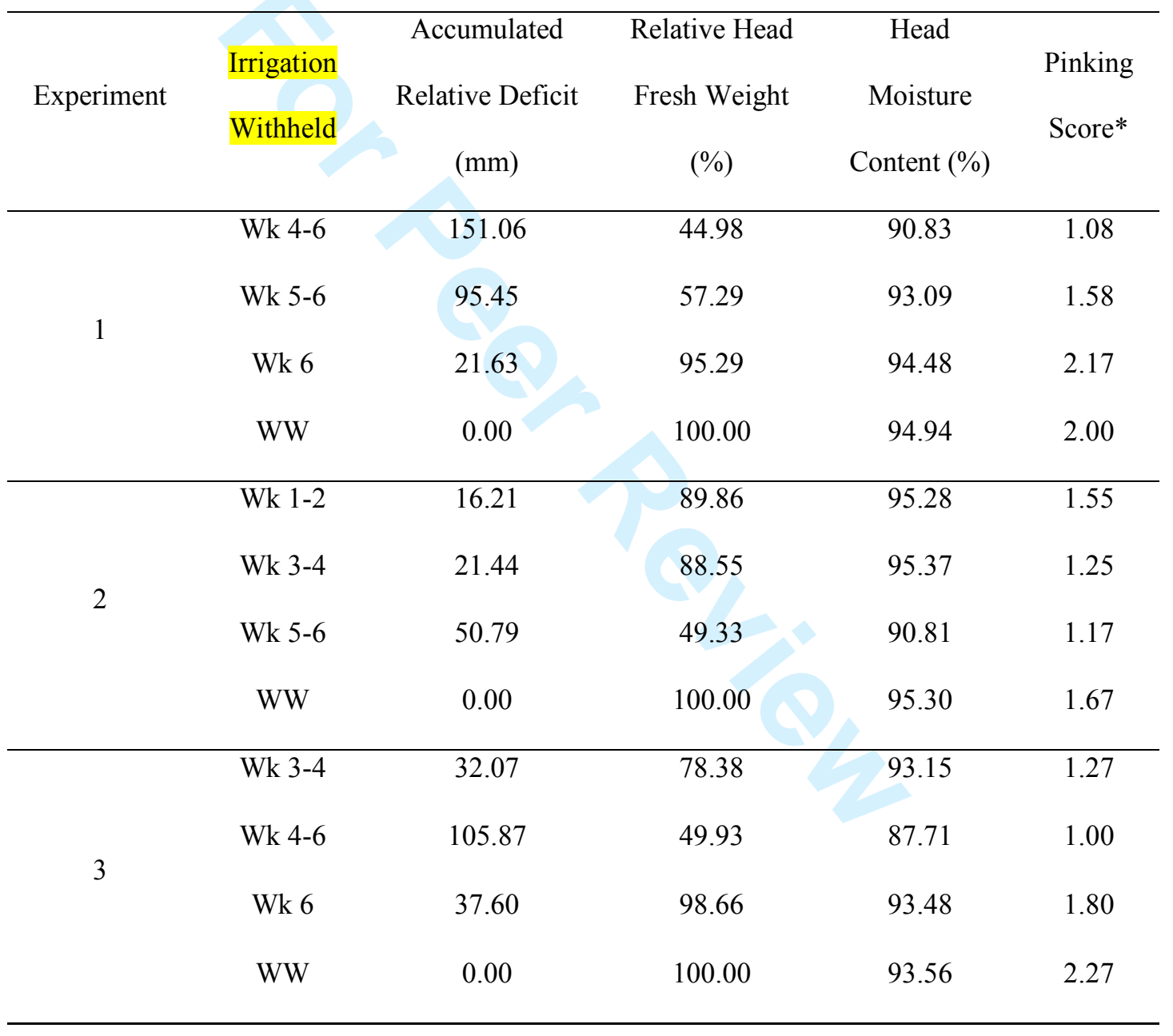

268

$269 *$ Wholehead pinking on the $10 \mathrm{~cm}$ visible length of ribs from the butt was scored after ten days

270 of storage using visual assessment criteria, marking from 1 (absence of pinking), through 2

271 (pink colouration on $1 / 3$ of rib tissue), 3 (pink colouration on $2 / 3$ of rib tissue) to 4 (pink

272 colouration on all of rib tissue).

12 
FIGURES

274

275

Figure 1.

276

Effect of withholding irrigation on deficit incurred and fresh weight.

277 Effect of timing and duration of withholding irrigation on the accumulated relative deficit and 278 relative head fresh weight (relative to well-watered control) across the three experiments. Black 279 bars $=$ accumulated relative deficit $(\mathrm{mm})$, white bars $=$ relative head fresh weight $(\%)$. Bars 280 represent means + - SEM. Within each variable, bars labelled with different lower case letters 281 are significantly different at $P \leq 0.05$ according to Tukey's test (a-c for accumulated relative 282 deficit and A-B for relative head fresh weight). Wk = week. $\mathrm{n}=12$ for $\mathrm{Wk} 1-2, \mathrm{n}=24$ for other 283 treatments.

284

285

286

287

288

289

290

291

292

293

294

295

296
Figure 2.

Deficit relationship with head fresh weight.

Effect of accumulated relative deficit on relative head fresh weight (relative to well-watered control) across the three experiments. Points represent means +/- SEM.

\section{Figure 3.}

Irrigation scheme effect on wholehead pinking.

Effective of timing and duration of withholding irrigation on pinking score across the different treatments in the three experiments. Points represent means $+/-$ SEM. Bars labelled with different lower case letters are significantly different at $P \leq 0.05$ according to Tukey's test. Wk = week. $\mathrm{WW}=$ well-watered control. $\mathrm{n}=12$ for $\mathrm{Wk} 1-2, \mathrm{n}=24$ for other treatments. 
297

298

299

300

301

302

\section{Figure 4.}

Head fresh weight relationship with wholehead pinking.
6
7

8

10

11

12

13

14

15

16

17

18

19

20

21

22

23

24

25

26

27

28

29

30

31

32

33

34

35

36

37

38

39

40

41

42

43

44

45

46

47

48

49

50

51

52

53

54

55

56

57

58

59

60
Relationship between relative head fresh weight (relative to well-watered control) and observed pinking score. Points represent means +/- SEM. 
1

2

3

4

5

8

9

10

11

12

13

14

15

16

17

18

19

20

21

22

23

24

25

26

27

28

29

30

31

32

33

34

35

36

37

38

39

40

41

42

43

44

45

46

47

48

49

50

51

52

53

54

55

56

57

58

59

60

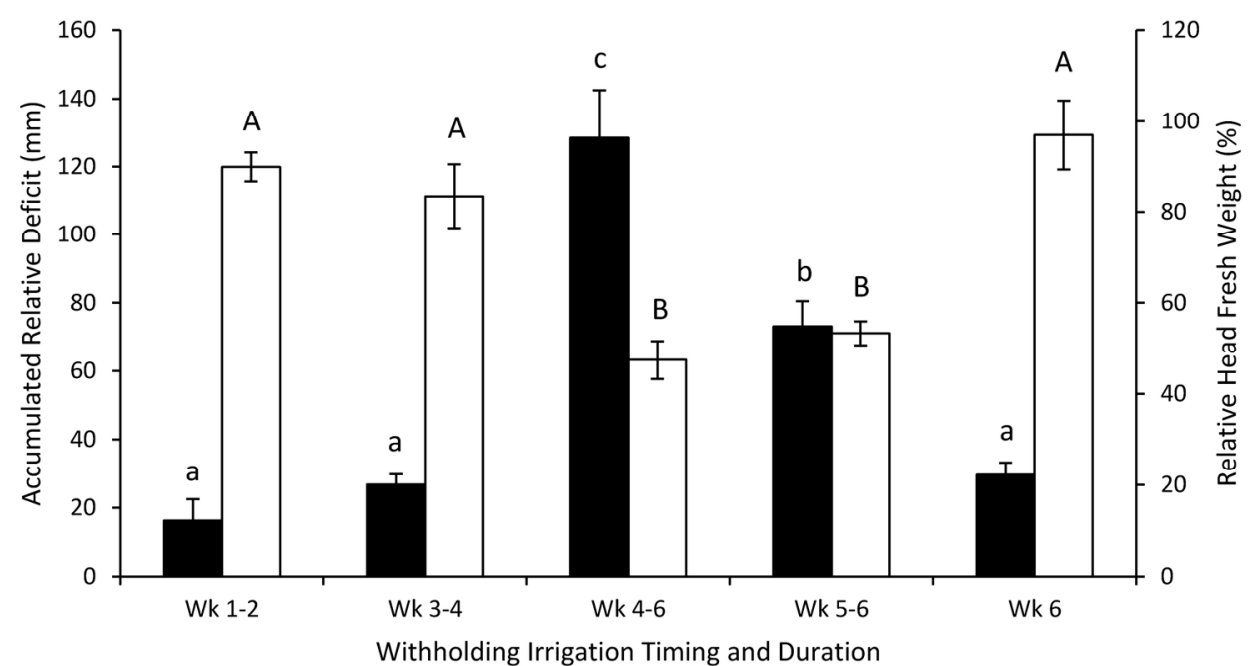

Figure 1.

Effect of withholding irrigation on deficit incurred and fresh weight.

Effect of timing and duration of withholding irrigation on the accumulated relative deficit and relative head fresh weight (relative to well-watered control) across the three experiments. Black bars $=$ accumulated relative deficit $(\mathrm{mm})$, white bars $=$ relative head fresh weight $(\%)$. Bars represent means $+/-$ SEM. Within each variable, bars labelled with different lower case letters are significantly different at $P \leq 0.05$ according to Tukey's test (a-c for accumulated relative deficit and A-B for relative head fresh weight). Wk = week. $n=12$ for Wk $1-2, n=24$ for other treatments.

$86 \times 46 \mathrm{~mm}(600 \times 600$ DPI $)$ 


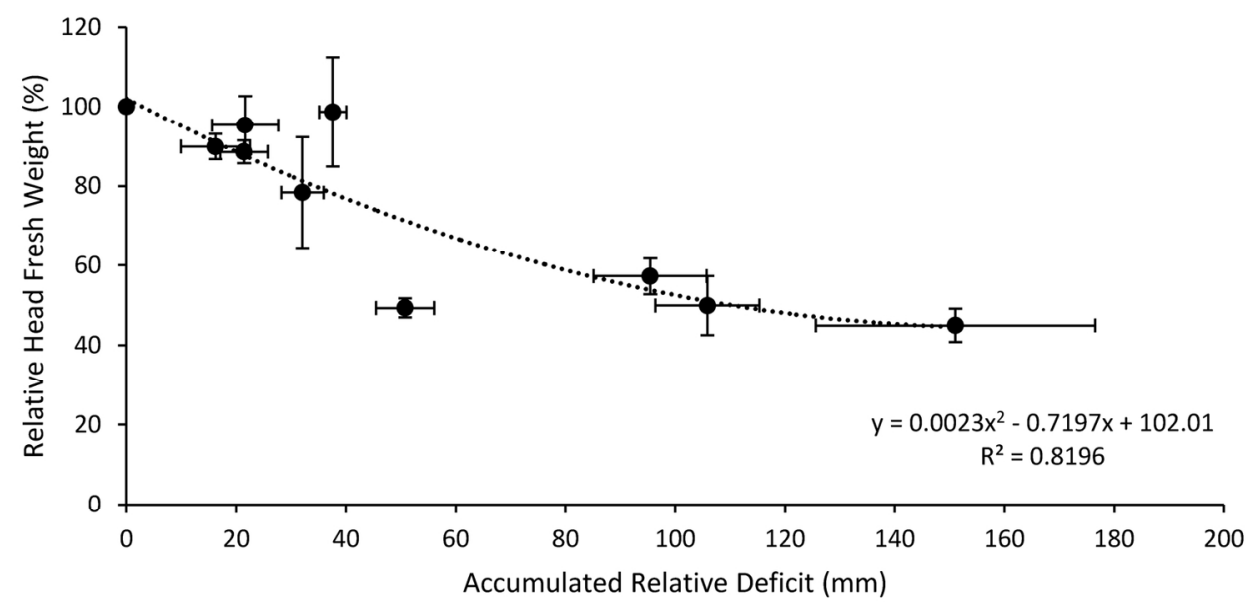

Figure 2.

Deficit relationship with head fresh weight.

Effect of accumulated relative deficit on relative head fresh weight (relative to well-watered control) across the three experiments. Points represent means +/- SEM.

$75 \times 37 \mathrm{~mm}(600 \times 600 \mathrm{DPI})$ 
Figure 3.

Irrigation scheme effect on wholehead pinking.

Effective of timing and duration of withholding irrigation on pinking score across the different treatments in the three experiments. Points represent means +/- SEM. Bars labelled with different lower case letters are significantly different at $\mathrm{P} \leq 0.05$ according to Tukey's test. Wk $=$ week. WW $=$ well-watered control. $n=12$ for Wk $1-2, n=24$ for other treatments.

$80 \times 43 \mathrm{~mm}(600 \times 600 \mathrm{DPI})$ 


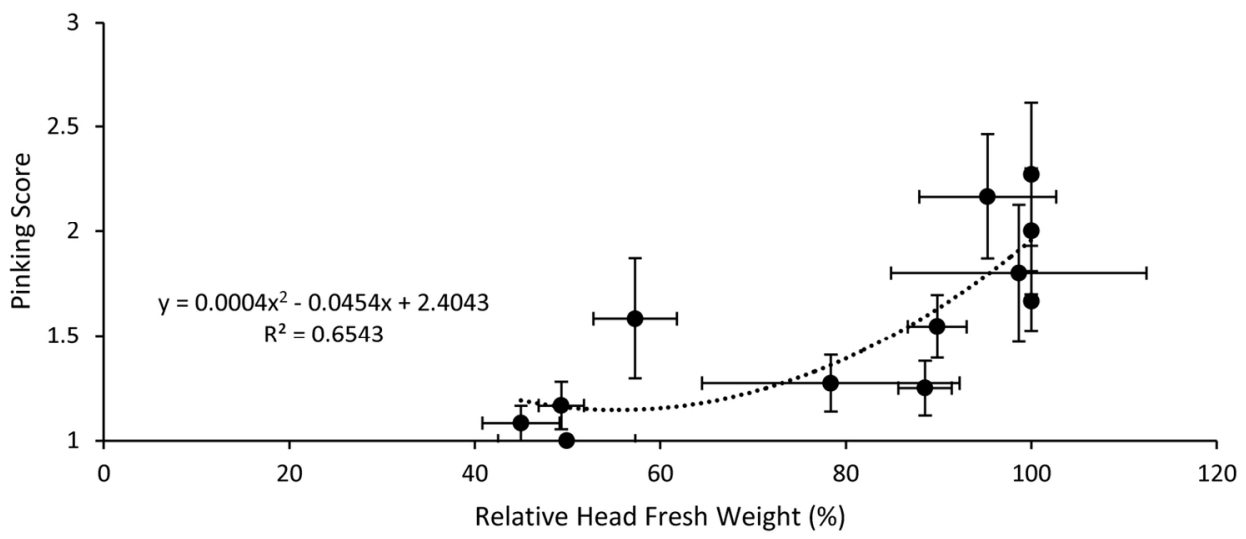

Figure 4.

Head fresh weight relationship with wholehead pinking. Relationship between relative head fresh weight (relative to well-watered control) and observed pinking score. Points represent means +/- SEM.

$70 \times 31 \mathrm{~mm}(600 \times 600 \mathrm{DPI})$ 